\title{
Characterisation of contaminants in sediments - effects of bioavailability on impact
}

J. Parsons ${ }^{1}$, M. Jesus Belzunce Segarra ${ }^{2}$, G. Cornelissen ${ }^{3}$, Ö. Gustafsson ${ }^{3}$, T. Grotenhuis ${ }^{4}$, H. Harms ${ }^{5}$, C.R. Janssen ${ }^{6}$, J. Kukkonen ${ }^{7}$, P. van Noort ${ }^{8}$, J.J. Ortega Calvo ${ }^{9}$ and O. Solaun Etxeberria ${ }^{2}$

${ }^{1}$ Institute for Biodiversity and Ecosystem Dynamics, University of Amsterdam, Amsterdam, The Netherlands

${ }^{2}$ Marine Research Division, AZTI Foundation, Pasajes, Spain

${ }^{3}$ Department of Applied Environmental Research, Stockholm University, Stockholm, Sweden

${ }^{4}$ Wageningen University, Wageningen, The Netherlands

${ }^{5}$ UFZ - Centre for Environmental Research, Leipzig, Germany

${ }^{6}$ Laboratory of Environmental Toxicology, Ghent University, Ghent, Belgium

${ }^{7}$ University of Joensuu, Joensuu, Finland

${ }^{8}$ RIZA, Lelystad, The Netherlands

${ }^{9}$ IRNAS, CSIC, Sevilla, Spain

\section{INTRODUCTION}

The total concentration of a compound in sediment provides an approach for the estimation of the level of contamination. Such an analysis provides information on the distribution patterns of contaminants along the river basin, estuaries and littoral, information that is needed for spatial and temporal monitoring studies. These data are also used by regulatory bodies to estimate the potential risk. However, these measurements are often inadequate to assess bioavailability and toxicity to organisms. Not all of the sediment-bound contaminant is readily available for organisms. The impact of contaminants on sediment biota depends on their bioavailability, i.e. the extent to which they can be taken up by sediment organisms or the extent they cause adverse effects.

An assessment of the risks of sediment contaminants should therefore include consideration of the bioavailability of the contaminants. Sediment quality criteria are often derived from water quality criteria by multiplication of the latter by sediment to water partition coefficients. Although, this equilibrium partitioning model has been successful in 
accounting for the distribution of functionally diverse chemicals (both metals and organic compounds) in many laboratory-based sorption studies on a wide range of soils and sediments, the ability of this procedure to account for the toxicity of the chemical has been less successful. Despite this latter observation, this simple approach has received broad recognition and formed the basis for several environmental quality standards.

These widely employed phase-distribution models based on partitioning with bulk sediment, or organic carbon for hydrophobic organic compounds (HOCs), developed in simplified laboratory systems, are, however, frequently unable to accurately predict the actual solid-water distribution of chemicals in aquatic field environments. The results from longterm sorption experiments, and particularly from field observations of phase distributions of HOCs, have made it increasingly clear that equilibrium-based partitioning models may not be universally applicable since: (i) a fraction of the contaminant is frequently seen to exhibit very slow sorption or desorption kinetics, (ii) solid-water distribution coefficients of some organic certain compounds in the field are far in excess of expectations from equilibrium partitioning and (iii) sorption isotherms exhibit nonlinearity.

These observations of non-equilibrium sorption have important consequences for the effects of contaminants in sediment since it is often assumed that uptake occurs through the water phase. Under non-equilibrium conditions the bioavailability of a sorbed compound will be determined by the kinetics of desorption to the aqueous phase. A realistic assessment of the impact of contaminants on sediment quality is therefore only possible if the actual bioavailability of the contaminants is included. This is essential to assess both the potential effects of contaminants on sediment biota as well as the fate of contaminants in sediment and the potential for bioremediation. In order to achieve this we need to know which part of the total is in fact the bioavailable fraction and we need methods to measure this fraction easily.

Recent research on the sorption processes, bioaccumulation and toxicity of contaminants in sediments has resulted in new insights into the mechanisms controlling the bioavailability of metals and organic contaminants in sediments. In addition, new biomimetic methods have been developed in which bioavailable fractions can be measured readily. Much of this work has been carried out in European projects such as WELCOME, ABACUS and LIBERATION. This chapter discusses these recent developments and how they may be included in impact assessment of contaminants in sediment.

\section{BIOAVAILABILITY OF METALS FOR BENTHIC ORGANISMS}

Unlike HOCs, there is no universally accepted method, such as the correlation between Kow and lipid-based concentration, to estimate the uptake, accumulation and toxicity of metals and organometals in benthic organisms. The wide range of their chemical properties and their interaction with environmental factors and the fact that the way that organisms physiologically 'handle' metals and organometals greatly differs from one species to another, complicate the task of assessing the accumulation, toxicity and the transfer of sedimentary metals and organometals in the benthic food chain.

There are a number of reactions and factors that control metal bioavailability in sediments. Indeed, metal bioavailability is controlled to varying degrees by factors such as 
sulphides, organic carbon, carbonates, redox state, $p H$, physical disturbance and transport processes. Metal cations frequently implicated with contamination and associated with sulphides include $\mathrm{Cd}, \mathrm{Cr}, \mathrm{Cu}, \mathrm{Pb}, \mathrm{Ni}$, and $\mathrm{Zn}$. However, these metals are often bound to a variety of sediment fractions of $\mathrm{Fe}$ and $\mathrm{Mn}$ oxides and organic materials and ranging from easily extractable (and bioavailable) to resistant residual mineral phases [e.g. 1-6]. There are a number of comprehensive reviews and guidance documents dealing with major aspects of assessing sediment quality and metal bioavailability $[1,7-12]$. Literature on metal contaminated sediments generally indicates that environmental risk assessments and sediment quality criteria based on the bioavailable metal fraction is clearly superior to "total" metal concentrations.

During the past decade the equilibrium partitioning (EqP) approach for deriving benchmark sediment quality guidelines has received increasing attention from both academics and regulators. This approach is based on the assumption that the primary toxicity of a chemical is correlated to the pore water concentration, suggesting that it is a major route of exposure [13]. However, this route of exposure does not include uptake from ingestion of contaminated sediment particles and overlying waters which have been shown to be important routes of exposure for some benthic organisms [14-16].

For divalent metals, including $\mathrm{Cu}, \mathrm{Cd}, \mathrm{Ni}, \mathrm{Pb}$, and $\mathrm{Zn}$, an equilibrium/bioavailability linkage was observed with the procedurally defined "acid volatile sulphide" (AVS) and "simultaneously extracted metal" (SEM) fractions [13, 17-19]. There have been many studies since the 1990s describing the important role of the AVS fraction in the binding metals in anoxic sediments and the use of this concept for predicting the absence (and recently, the occurrence) of toxicity [e.g. 17-28]. The AVS fraction contains the relatively labile Fe and $\mathrm{Mn}$ monosulphides as the dominant component and trace metals such as $\mathrm{Cd}, \mathrm{Cu}, \mathrm{Pb}, \mathrm{Ni}$, and $\mathrm{Zn}$ tend to displace Fe and Mn from sulphide. This metal sulphide form is essentially nonbioavailable to benthic organisms. On the other hand, if the total concentration of the metals is greater than the concentration of AVS, some metal fraction potentially is bioavailable and could cause toxicity if no other metal ligands are available (e.g., Fe and Mn oxyhydroxides, organic carbon, carbonates). No toxicity should occur if $\Sigma$ SEM/AVS $<1$, since all of the free metal available would be bound to the AVS phase (e.g. zinc sulphide). Using the $\Sigma$ SEM AVS difference instead of the SEM/AVS ratio gives additional insight into the magnitude by which AVS binding has been exceeded. At a molar $\Sigma$ SEM - AVS difference $<0$ no effects are expected to occur. It should be noted that although this approach ( $\Sigma$ SEM - AVS $<0$ or $\Sigma S E M / A V S<1$ ) can predict when there will not be toxicity with a high degree of certainty, it does not predict whether or not there will be toxicity if $\Sigma$ SEM - AVS $>0$ or $\Sigma$ SEM/AVS $>1$. Next to AVS, organic carbon has also been shown to be an important partitioning phase for metals in sediment and in water. Thus, when the excess $\Sigma$ SEM is normalized to the organic carbon concentration (i.e. $\Sigma(\mathrm{SEM}-\mathrm{AVS}) / f_{\text {oc }}$ ), it has been found in comparisons with toxicity data that a boundary for chronic effects exists when $\Sigma$ SEM - AVS $/ f_{\mathrm{oc}}$ is in excess of 100 to $150 \mu \mathrm{mol} / \mathrm{g}$ oc, allowing for the prediction of toxicity.

In their excellent overview paper, Ankley et al. [17] summarized these and other potential approaches for predicting bioavailability of metals in sediments and for establishing sediment quality criteria (SQC). They discerned four approaches: 
1. comparison of molar AVS concentrations to the summed molar concentrations of the five simultaneously extracted metal with the AVS;

2. measurement of interstitial water metal concentrations and calculations of summed interstitial water criteria toxic units (IWCTU) for the five metals, based upon final chronic values from water quality criteria documents;

3. calculation of summed IWCTU based on sediment AVS concentrations and metalspecific partitioning of the metals to organic carbon;

4. calculation of summed IWCTU based upon partitioning of the metals to a minimum binding phase sorbent (e.g. chromatographic sand).

They concluded that, at that moment, approaches 1 and 2 were the most useful in terms of predicting metal bioavailability and deriving SQC, and that more research was needed to implement the other two approaches. They also stated that further research was needed to understand processes controlling bioaccumulation of metals from sediments by benthic organisms, as well as metal accumulation by pelagic species that ingest metal contaminated benthos.

Much of the controversy on the potential use of some of the approaches described above result from lack of knowledge on long-term, sub-lethal effects of metal contaminated sediments, the importance of other exposure routes (e.g. dietary; sediment ingestion), and the confusion between bioaccumulation based observations and toxicity effects. On the latter issue, caution should be used when using tissue concentrations to predict hazards or risks, as some metals are essential, such as $\mathrm{Cu}$ and $\mathrm{Zn}$ and are actively regulated by organisms, while others tend to store metals in detoxified forms.

In their examination of the SEM/AVS approaches, Lee et al. [29] demonstrated - using four marine benthic species - that metal concentrations ( $\mathrm{Cd}, \mathrm{Ni}, \mathrm{Ag}$ and $\mathrm{Zn}$ ) in animal tissue correlated with metal concentrations from sediments, but not with porewater, across a range of reactive sulphide concentrations. They conclude that their results contradict the notion that metal bioavailability is controlled by geochemical equilibration (i.e. approaches summarized above) of metals between porewater and reactive sulphides. Although, numerous studies have shown that metal accumulation does not necessarily lead to adverse effects and the latter assessment is usually the main driver for SQC derivation and risk assessments, the studies of these authors and others do indicate that there is uncertainty associated with the use of geochemical equilibrium approaches for accounting for metal bioavailability in sediments.

Lee et al. [29] suggest that, especially under circumstances of moderate to low sediment contamination, exposure of organisms may occur via ingestion of particles and effects on populations may be manifested via chronic toxicity. Their recommendations for advancing our understanding metal bioavailability in sediments and fully evaluating how broadly the AVS-normalized approaches can be applied include (1) consideration of chronic responses and mechanisms that link toxicity and accumulation, and (2) laboratory or field effect studies which simulate naturally occurring contaminated sediments.

One such long-term field study was recently conducted by Burton et al. [30]. It was aimed at assessing the zinc concentrations in freshwater sediments that are tolerated by benthic macroinvertebrate communities and to determine whether there is a relationship with the SEM-AVS model. The results of this study were used to evaluate possible inter- 
relationships of site-specific characteristics taking into account short-term to seasonal variability with its associated effects on dietary uptake and oxic and anoxic gradients. Test sites included: Schmallenberg. Germany; Ankeveen, The Netherlands; Pallanza, Italy; and Biesbosch, The Netherlands. In both the lake and riverine systems, one sediment type was high in AVS and one was low in AVS, which resulted in Zn spiked sediments that ranged from low to high SEM/AVS ratios. The colonization trays were sampled seasonally, ranging from 6 to 37 weeks of exposure (one to three sampling periods), and evaluated using several appropriate benthic indices. Results of the field evaluations at the four test sites confirmed the validity of the AVS-SEM model, predicting benthic macroinvertebrate effects correctly $92 \%$ of the time. The AVS-SEM model predicts that there should be no toxicity to benthic invertebrates when the SEM/AVS ratio is less than one or when carbon normalized AVS fraction below $150 \mu \mathrm{mol} / \mathrm{g}$ OC. In sediments where the SEM/AVS ratio or the AVS and organic carbon normalized fractions exceeded 8 and $583 \mu \mathrm{mol} / \mathrm{g} \mathrm{OC}$, toxicity was observed from the $\mathrm{Zn}$ spiked sediments. Conversely, when the SEM/AVS ratio or carbon normalized AVS fractions were below 2 or $100 \mu \mathrm{mol} / \mathrm{g} \mathrm{OC}$, no toxicity was observed. Total $\mathrm{Zn}$ concentrations in sediments showed no relationship to benthic effects, with Ankeveen sediments being non-toxic at $913 \mathrm{mg} \mathrm{Zn} / \mathrm{Kg} \mathrm{DW}$, while Pallanza sediments were toxic at 175 $\mathrm{mg} \mathrm{Zn/Kg} \mathrm{DW.} \mathrm{Contrary} \mathrm{to} \mathrm{the} \mathrm{concerns} \mathrm{expressed} \mathrm{by} \mathrm{Lee} \mathrm{et} \mathrm{al.} \mathrm{[29]} \mathrm{and} \mathrm{others,} \mathrm{this} \mathrm{long-}$ term, experimental field study - using long-term population and community level endpoints clearly supports the SEM/AVS-based approaches (see above) for evaluating and predicting metal bioavailability (based on effects) in sediments.

Recently, Di Toro et al. [31] demonstrated the use of 'water column' biotic ligand model - a predictive metal bioavailability tool - for explaining metal toxicity in sediments. The 'water column' biotic ligand model (BLM) [32] is used to compute the effect concentration in the aqueous phase that results in a metal concentration at the site of action (the biotic ligand) that produces $x \%$ mortality. It accounts for the varying bioavailability of dissolved metal due to metal complexation with inorganic anions and with dissolved organic carbon by relating toxicity to the free metal ion activity. The BLM also accounts for the protective effects of the hardness cations and the effect of $\mathrm{pH}$ as a competitive equilibrium at the biotic ligand following a model originally proposed by Pagenkopf in 1983 [12] (see Paquin et al. [33] for a comprehensive review of the historical development of the BLM). Using a slightly different experimental and computational approach, De Schamphelaere and Janssen, De Schamphelaere et al. and Heijerick et al. [34-42] have demonstrated that the BLM concept also holds for predicting chronic toxicity of various metals to different freshwater species.

The sediment BLM (sBLM) proposed by Di Toro et al. [31] is an extension of the water column BLM in which porewater DOC is not considered (based on the analysis of the importance of this factor for determining sediment toxicity); instead sediment POC is included. This study demonstrates that the organic carbon normalized excess SEM (SEMx,OC $\left.=(\mathrm{SEM}-\mathrm{AVS}) / f_{O C}\right)$ can be used to predict the sediment concentration at which metal toxicity is observed. The authors use the biotic ligand model to compute the $L C_{50}$ concentration of metal on sediment particulate organic carbon, SEMx,oc, that is in equilibrium with the $L C_{50}$ in pore water - following the precepts of the Equilibrium Partitioning (EqP) model - and in equilibrium with the critical concentration at the site of 
action (the biotic ligand). It is concluded that a sediment biotic ligand model can be successfully developed that avoids the complications of explicitly modeling the pore water chemistry. The sediment concentration is computed by assuming equilibrium between the critical metal concentration on the biotic ligand and sediment particulate organic carbon. This concentration is compared to the sediment metal concentration in excess of AVS, normalized to the organic carbon concentration of the sediment (SEM - AVS) $/ f_{O C}$.

\section{BIOAVAILABILITY OF HYDROPHOBIC ORGANIC CHEMICALS FOR BENTHIC ORGANISMS}

\subsection{Sorption of hydrophobic organic chemicals}

The sorption of hydrophobic organic chemicals (HOCs) is an important process because it governs the fate, transport and ecotoxicological risks of soil- and sediment-bound chemicals. Around 1980 it was discovered that the organic matter (OM) in soils and sediments was the principal factor controlling sorption of HOCs and it was proposed to normalize sediment-water distribution ratios to the Total Organic Carbon (TOC) content [43, 44]. In the 1990s and 2000s, several findings like nonlinear sorption isotherms [45-47], multiphasic desorption kinetics [48, 49] and strongly elevated TOC-water distribution ratios $\left(K_{T O C}\right)$ in the field $[50,51]$ led to the suggestion of a dual-mode sorption concept $[45,48,49]$. In this concept, the $\mathrm{OM}$ is regarded to be composed of two domains, one showing linear absorption and one showing nonlinear adsorption. The absorption domain has been proposed to consist of amorphous OM like humic/fulvic substances and lignin [45], whereas harder, more condensed moieties like coal and kerogen contribute to the adsorption domain [45, 48, 49]. The results of previous research on sorption properties of various geosorbent constituents have been summarized in excellent reviews [52-54]. In an attempt to characterize these two domains it was found that persulfate oxidation could oxidize the amorphous OM fraction together with the bioavailable PAH. [55]. Characterization of the SOM before and after bioremediation of PAH contaminated sediments showed that the condensed SOM domains are situated in the humin fraction of the SOM. It was reasoned that the condensed organic matter is less polar than expanded organic matter, which is in accordance to several studies that reported a negative correlation between SOM polarity and the affinity of SOM for hydrophobic organic contaminants [56-63].

One particularly strongly sorbing form of TOC is Black Carbon (BC) [51, 64-66]. BC is formed by combustion processes; the two main forms are soot ( $\mathrm{BC}$ formed by condensation reactions) and charcoal (charred residues of the original fuel). Part of the $\mathrm{BC}$ in the environment stems from combustion of biomass (forest fires, residential wood burning); part of it is from fossil fuel combustion (traffic, industry, coal, oil). So far, sorption to BC has mainly been studied for pure soots and charcoals [51, 64-66]. This research has shown that sorption to $\mathrm{BC}$ can be exceptionally strong, with $\mathrm{BC}$-water distribution ratios, $K_{B C}$, exceeding $\mathrm{OC}$-water ones by a factor of 100 or more. Generally, BC contents are about $1-15 \%$ of TOC $[66,67]$, so in several cases $\mathrm{BC}$ can be expected to contribute more strongly to overall sorption than all the other OM constituents.

A BC-inclusive Freundlich sorption model is 
$C_{S}=f_{O C} K_{O C} C_{W}+f_{B C} K_{F, B C} C_{W}^{n_{F}}$

where $f_{O C}$ and $f_{B C}$ are the sediment mass fractions of $O C$ and $\mathrm{BC}$, respectively, $K_{O C}$ is the OC-water distribution coefficient $(\mathrm{L} / \mathrm{kg}), C_{W}$ is the aqueous concentration $(\mu \mathrm{g} / \mathrm{L}), K_{F, B C}$ is the Freundlich BC-water distribution ratio $\left[\left(\mu \mathrm{g} / \mathrm{kg}_{\mathrm{BC}}\right) /(\mu \mathrm{g} / \mathrm{L})^{n}\right]$ and $n_{F}$ is the Freundlich exponent of $\mathrm{BC}$ sorption. A concentration dependence appears in the $\mathrm{BC}$ term because of the nonlinearity of $\mathrm{BC}$ sorption.

In recent studies in the ABACUS project, the abovementioned model (eq. 1) is further evaluated for environmental $\mathrm{BC}$. The sorption characteristics of the $\mathrm{BC}$ after combustion were studied by determining sorption isotherms of sediment that was combusted at $375^{\circ} \mathrm{C}$. In order not to overlook processes occurring at low but environmentally relevant concentrations (in the $\mathrm{ng} / \mathrm{L}$ range), we determined isotherms over a wider concentration range $\left(C_{W}=0.0005-6 \mu \mathrm{g} / \mathrm{L}\right)$ than in previous BC sorption studies. The applied sorption method was the Polyoxymethylene-Solid Phase Extraction method (POM-SPE) recently developed by Jonker and Koelmans [65].

The importance of Black Carbon sorption for total sorption was determined after the OM and native sorbates had been removed by combusting five sediments at $375^{\circ} \mathrm{C}$ under air [70]. $K_{F, B C}$ was determined for $\mathrm{d}_{10}$-PHE (phenathrene) by measuring sorption isotherms in the combusted sediment that contained only minerals and $\mathrm{BC}$.

Example sorption isotherms for BC and TOC are presented in Figure 1.

Table 1

TOC and $\mathrm{BC}$ contents of the five studied sediments and Freundlich parameters of TOC and BC sorption (from [72])

\begin{tabular}{lllllll}
\hline Sediment & TOC (\%) & BC (\%) & $\begin{array}{l}\log K_{F, O C} \\
(\mu \mathrm{g} / \mathrm{kgOC}) /(\mu \mathrm{g} / \mathrm{L})^{n F}\end{array}$ & $n_{F, O C}$ & $\begin{array}{l}\log K_{F, B C} \\
\left(\mu \mathrm{g} / \mathrm{kg}_{\mathrm{BC}}\right) /(\mu \mathrm{g} / \mathrm{L})^{n F}\end{array}$ & $n_{F, B C}$ \\
\hline VAR & $0.120 \pm 0.003$ & $0.024 \pm 0.002$ & $5.03 \pm 0.04$ & $0.85 \pm 0.02$ & $4.97 \pm 0.14$ & n.e.d. \\
MEK & $21.03 \pm 0.12$ & $0.84 \pm 0.12$ & $5.40 \pm 0.14$ & $0.98 \pm 0.03$ & n.d. & n.d. \\
KUO & $1.39 \pm 0.07$ & $0.152 \pm 0.008$ & $5.12 \pm 0.10$ & $0.92 \pm 0.05$ & $5.07 \pm 0.11$ & n.e.d. \\
HOY & $3.30 \pm 0.02$ & $0.105 \pm 0.010$ & $4.76 \pm 0.07$ & $0.83 \pm 0.03$ & $5.4 \pm 0.2$ & n.e.d. \\
KET & $5.51 \pm 0.01$ & $0.720 \pm 0.010$ & $5.05 \pm 0.06$ & $0.93 \pm 0.03$ & $4.6 \pm 0.4$ & 0.54 \\
\hline
\end{tabular}

n.d., not determined due to very low $\mathrm{BC}$ content.

n.e.d., not explicitly determined but assumed to be equal to the $\mathrm{n}_{\mathrm{F}, \mathrm{BC}}$ of KET sediment for the calculation of Fig. 2.

The sorption isotherm of the original sediment was almost linear (Freundlich coefficient, $n_{F}>0.9$ ), whereas the isotherm of the $\mathrm{BC}$ remaining after the sediment combustion was highly nonlinear $\left(n_{F}=0.54\right)$. This shows that the $\mathrm{BC}$ sorption sites have a limited capacity. In Table 1, the sorption parameters for all five sediments are presented. The $K_{F, B C}{ }^{e n v}$, the sorption coefficient of environmental $\mathrm{BC}$, has been corrected for competition effects between the native PAHs and the added $\mathrm{d}_{10}$-PHE. 


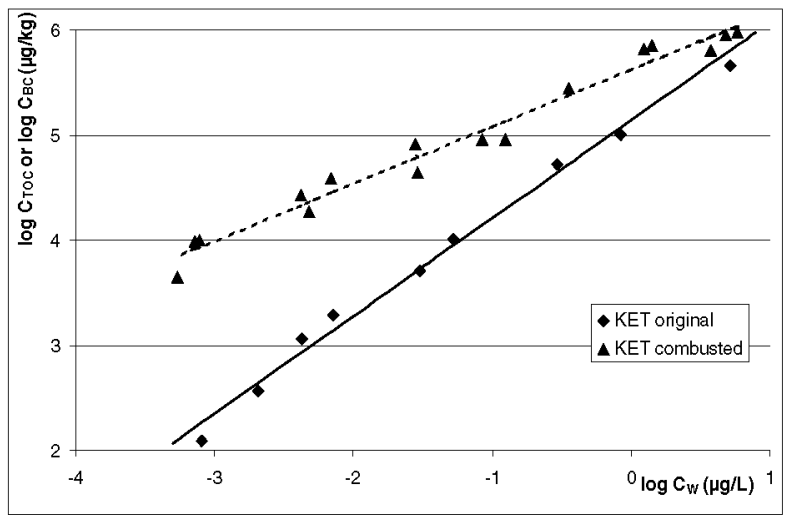

Fig. 1. Freundlich isotherms for $d_{10}-\mathrm{PHE}$ in original, unchanged KET sediment (closed diamonds, straight line) and combusted KET sediment [OM and all sorbates removed by $375^{\circ} \mathrm{C}$ combustion (triangles, dotted line)]. On the $y$-axis are $\log C_{T O C}\left(\mu \mathrm{g} / \mathrm{kg}\right.$ TOC; original sediment) and $\log C_{B C}(\mu \mathrm{g} / \mathrm{kg}$ $B C$, combusted sediment). The KET sediment is from the first major sedimentation area of River Rhine, a river that transports large amounts of contamination. Reprinted with permission from [71] Copyright 2004 American Chemical Society.



Fig. 2. Relative contribution of BC to total PHE sorption in five sediments: contaminated KET sediment from The Netherlands and four relatively pristine sediments from Eastern Finland. Data from [72]

On the basis of $\mathrm{BC}$ and TOC contents and the respective sorption coefficients, the relative contribution of $\mathrm{BC}$ to total sorption was calculated. This is shown in Figure 2.

It appears that at low aqueous PHE concentrations ( $\mathrm{ng} / \mathrm{L}$ and below), $\mathrm{BC}$ is a very important geosorbent constituent with respect to sorption (40-80\% of sorption is to the $\mathrm{BC}$ ). At higher concentrations $(\mu \mathrm{g} / \mathrm{L}), \mathrm{BC}$ sorption sites become saturated and $\mathrm{BC}$ sorption is overwhelmed by sorption to the other OM constituents. 
The effect of sorbate planarity on BC sorption was determined by measuring sorption isotherms for 4 compounds with the same $K_{O W}$ (planar anthracene (ANT), phenanthrene (PHE) and 4-PCB as well as for nonplanar 2,2'-PCB) to BC in combusted KET sediment. The sorption isotherms are shown in Figure 3. The $K_{F, B C}$ decreased in the order ANT (6.24) > PHE, 4-PCB $(5.62 ; 5.42)>2,2^{\prime}-\mathrm{PCB}(4.54)$. There is also a difference in BC sorption linearity between the nonplanar 2,2'-PCB and the three planar compounds: $\mathrm{BC}$ sorption of the nonplanar compound was almost linear $\left(n_{F, B C}=0.92\right)$, in contrast to the planar ones $\left(n_{F, B C}=\right.$ 0.54-0.70). This implies that at low concentrations (e.g. $1 \mathrm{ng} / \mathrm{L}$ ) $K_{B C}$ of 2,2'-PCB is much smaller than $K_{B C}$ of the other three compounds, whereas at high concentrations where BC sites become saturated, sorption is approximately equally strong for all compounds. The $K_{F, B C}$ and $n_{F}$ values for planar and nonplanar compounds imply that $\mathrm{BC}$ is far less important for sorption in the environmentally relevant nanogram per liter range for nonplanar 2,2'-PCB than for planar $\mathrm{ANT}, \mathrm{PHE}$ and $4-\mathrm{PCB}$, and that steric effects play an important role in $\mathrm{BC}$ sorption.

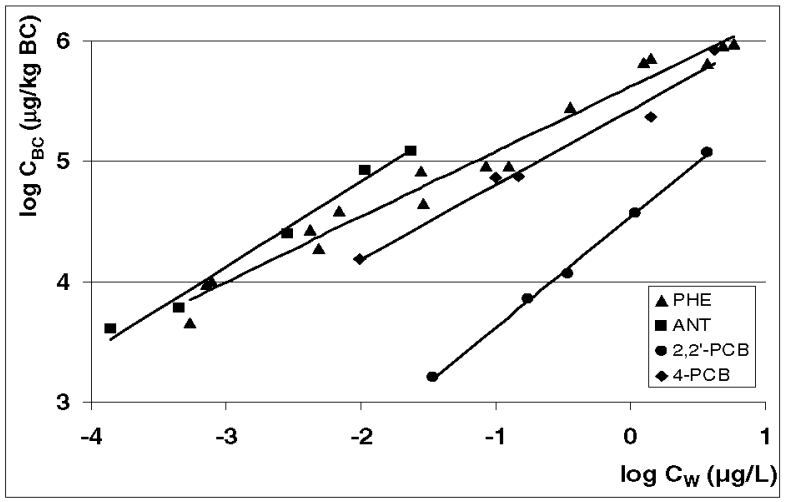

Fig. 3. BC-normalized Freundlich isotherms for $d_{10}-P H E$ (triangles), $d_{10}-A N T$ (squares), 4-PCB (diamonds) and 2,2'-PCB (circles) in combusted KET sediment (OM and all native sorbates removed by $375^{\circ} \mathrm{C}$ combustion). Lines obtained by linear regression. On the $x$-axis is $\log C_{W}(\mu \mathrm{g} / \mathrm{L})$, on the $y$ axis is $\log C_{B C}(\mu \mathrm{g} / \mathrm{kg} \mathrm{BC})$. Reprinted with permission from [73]. Copyright 2004 American Chemical Society.

The extent of adsorption onto black carbon depends on this number of accessible sites, apart from the magnitude of the equilibrium constant for adsorption onto a site. For the maximum capacities for adsorption of several PAHs and PCBs onto BC ( 5 different soots and 5 different soot-like materials) it was found that about $80 \%$ of the variation in maximum adsorption capacities for groups of sorbates (PAHs, non-ortho PCBs, mono-ortho-PCBs, and di-ortho-PCBs) could be explained by the variation in both sorbent carbon content and the relative magnitude of the area of the shadow of a sorbate molecule on a planar surface [72].

For mono-layer adsorption of low-polarity organic compounds onto black carbon it was recently proposed, based on literature data for the enthalpy of adsorption, that the enthalpy for 
the sorbate-sorbent interaction can be taken equal to that for the interactions in the pure solid state of the sorbate [75]. Furthermore, in the same study, for the entropy difference between the adsorbed and the solid state it was derived from literature data for chlorinated benzenes and PAHs that this difference can be taken equal to the entropy of melting $\left(\Delta S_{m}\right)$ minus 15 $\mathrm{J} / \mathrm{mol.K}$. Based on this the equilibrium constant for mono-layer adsorption, i.e. the Langmuir affinity, can be estimated to be equal to $\exp \left(\left(\Delta S_{m}-15 \mathrm{~J} / \mathrm{mol} . \mathrm{K}\right) / R\right) /$ solid solubility [75].

The existence of several different mechanisms for sorption of organic compounds by sediments can also be studied kinetically by performing desorption-to-water studies where the solute concentration in water is kept virtually zero by the presence of a strong additional sorbent such as Tenax [76]. From these type of studies, it was observed that, phenomenologically, desorption from sediment can be described on the basis of three distinct first-order kinetic steps: initially a fraction (the rapidly desorbing fraction) desorbs at a time scale of a few hours, followed by a second (the slowly desorbing fraction) desorbing at a time scale of a few days, and finally a third fraction (the very slowly desorbing fraction) desorbs on a time scale of several weeks [77].

It is important to note that the rate of desorption depends not only on the quantity of organic matter but also on the structure or quality of organic matter. For example, the decrease in the $\mathrm{O} / \mathrm{C}$ ratio in soil organic material was directly related to increased phenanthrene binding and hysteresis decreasing its desorption rate [78]. This observation was interpreted to mean that older more diagenetically processed organic matter binds certain organic contaminants to a greater degree. In a similar sense, a recent study examining the distribution of PAHs in two weathered sediments demonstrated that PAHs were preferentially associated with the lower density fraction of sediments containing detrital plant rather than soot carbon [79]. Further evidence that particle geochemistry affects PAH bioavailability is that coal derived particles have a greater $\mathrm{PAH}$ binding capacity and slower $\mathrm{PAH}$ desorption rates than silt/clay particles in sediment [80]. In additional field studies of PAH desorption, the rates were in the range of 0.016 to $0.08 \mathrm{~d}^{-1}$ [81]. Similarly, the desorption of selected nonpolar contaminants was found to only exhibit the slow or very slow desorption rates from field collected sediments compared to the desorption rates measured for laboratory-spiked sediments [82].

From a study on the kinetics of desorption of three organochlorine compounds from a sediment, it was found that the fraction of the compounds in the rapidly desorbing domain was sorbed by a linear isotherm, whereas the fraction in the slowly desorbing domain was sorbed by a non-linear Langmuir isotherm, which was different from the Langmuir isotherm for the very slowly desorbing fraction [49]. For several contaminants in some sediments, variation in organic carbon normalized partition coefficients was greatly reduced by normalization to the fraction of sorbates in the rapidly desorbing domain [74, 75]. Furthermore, sorption in the slowly and very slowly desorbing domains of some sediments was subject to competition phenomena $[85,86]$. That suggests that in general the rapidly desorbing domain can be related to the fraction that is linearly sorbed and that the slowly and very slowly desorbing domains are associated with adsorption.

The adsorption in the very slowly desorbing domain seems to be adsorption onto black carbon since the extent of sorption in the rapidly desorbing domain was higher for non-planar 
compounds in several sediments [87] and since the extent of sorption in the very slowly desorbing domain of two sediments was found to be higher for planar compounds as compared to non-planar PCBs [88], similarly as for adsorption onto activated carbon. For the slowly desorbing domain the mechanism is not yet clear. From desorption studies on two sediments, it was suggested that the slowly desorbing domain is perhaps related to sorption by pore deformation in glassy natural organic matter and that the very slowly desorbing domain is perhaps related to sorption by black carbon type of materials [88]. Nevertheless, ongoing investigations suggest (van Noort, unpublished results) that the slowly desorbing domain may be associated with black carbon as well.

\subsection{Bioavailability of hydrophobic organic chemicals for accumulation in sediment organisms}

Sediment characteristics, like the amount of total organic carbon [13] and the geochemistry of organic matter [89], are shown to affect the bioavailability sedimentassociated contaminants to sediment-dwelling organisms. Recent research has demonstrated that within a single sediment type, that the rapidly desorbed fraction of sediment-associated contaminant is correlated to the bioavailable fraction for various environmentally present and laboratory-spiked PAHs [90]. This confirms earlier modelling efforts suggesting that the desorption rate from sediment was critical for the bioaccumulation of sediment-associated contaminants [91]. Thus, it appears that differences in bioavailability across sediments may be explained by the ability of contaminants to desorb from sediments.

A series of desorption and bioavailability experiments was carried out with seven laboratory dosed sediments as part of the ABACUS project $[92,93]$. The objectives of this work were to confirm the potential applicability of sediment desorption kinetics as surrogates for bioavailability in two freshwater benthic organisms, Lumbriculus variegatus and Diporeia spp. exposed to several types of sediment. The sediments were characterized extensively and they exhibited a wide range of biogeochemical characteristics. There were some interesting correlation or lack of correlations in the obtained data set. Neither OC, total nitrogen or soot carbon showed any correlation with the more biologically derived fractions of the organic matter like pigment, lignin, and lipid components. Moreover, the $\mathrm{NaOH}$ extractable portions of the organic matter, which is usually comprised of the operationally defined refractory humic substances (i.e., humic and fulvic acids) were generally inversely correlated with the pigment and lignin portions of the sediment. The lignin, pigment, and lipid measures were generally strongly related. One interpretation of these observations taken together is that the plant derived materials intercorrelate [92].

The desorption rates and fractions were substantially different among the compounds and sediments. The desorption rates $\left(k_{\text {rap }}\right.$ and $k_{\text {slow }}$ ) for $\mathrm{BaP}$ (benzo[a]pyrene) were generally slower in most sediments than for HCBP $\left(2,2^{\prime}, 4,4^{\prime}, 5,5^{\prime}\right.$-hexachlorobiphenyl). The desorption rate was not correlated with the amount of OC in the sediment. For PY (pyrene) and TCBP (3,3',4,4'-tetrachlorobiphenyl), the compound desorption was most rapid for PY relative to TCBP in all desorption pools. As with $\mathrm{BaP}$ and HCBP the rate of desorption was not correlated with the amount of $\mathrm{OC}$ in the sediment. In general, the two PAH and the coplanar TCBP behaved similarly while the non-coplanar HCBP seemed to behave differently with 
respect to the sediment characteristics that appear to control desorption. The factors that produced positive correlations with the desorption flux and the size of the rapidly and slowly desorbing fractions of the PAH and TCBP were the pigments and the lipids in the sediment. HCBP did not behave at all like the more planar compounds. Fewer significant correlations were found because the rates were not very different among the sediments. HCBP was the only compound to exhibit an interaction with $\mathrm{OC}$ but the negative correlation of the desorption rate constant for the rapidly desorbing pool versus OC was not significant $(p=$ 0.83) [92]. Correlations between the toxicokinetic parameters and the factors representing the desorption kinetics were examined to describe the variation in the bioavailability across the range of sediments. In the $L$. variegates assay, for the two PAH congeners, the flux off the particles (i.e., the rate constant times the concentration in a compartment) was directly proportional to the rate of bioaccumulation as determined by the uptake coefficient. The flux out of the sediment can be related to the uptake rate constant $\left(k_{s}\right)$ because $k_{s}$ is directly proportional to the flux into the organism as represented by $k_{s} C_{s}$ since $C_{s}$ is constant. Thus, in general, the faster the flux out/off particles the faster the flux into the organism. However, the correlation for PY, the more water-soluble $\mathrm{PAH}$ was less significant $0.1 \geq p \geq 0.05$ perhaps reflecting the difficulty in obtaining accurate kinetic parameters because of the sampling scheme. Diporeia spp. exhibited trends between the desorption characteristics and the bioaccumulation of contaminants but did not show as many positive correlations as those found for $L$. variegatus. The best description of the bioavailability was the log BSAF (biota sediment accumulation factor) regressed against the fraction rapidly desorbed $\left(F_{\text {rapid }}\right)$ across all sediments and compounds for both species, $r^{2}=0.67$ and 0.66 for $L$. variegatus and Diporeia respectively [93].

Combining the equation to calculate BSAF

$$
B S A F=\frac{C_{\text {lipid }}}{C_{T O C}}=\frac{C_{\text {lipid }}}{C_{S} / f_{T O C}}=\frac{K_{\text {lipid }} C_{W}}{C_{S} / f_{T O C}}
$$

with the BC-inclusive sorption model

$$
C_{S}=f_{O C} K_{O C}+f_{B C} K_{F, B C} C_{W}^{n}
$$

yields

$$
B S A F=\frac{K_{\text {lipid }}}{K_{O C}+\frac{f_{B C}}{f_{O C}} K_{F, B C} C_{W}^{n-1}}
$$

where $f_{O C}$ is the $O C$ fraction in the sediment, $C_{W}$ is the aqueous $\mathrm{HOC}$ concentration $(\mu \mathrm{g} / \mathrm{L})$, $K_{\text {lipid }}(\mathrm{L} / \mathrm{kg})$ is the lipid-water partitioning coefficient, $K_{O C}$ is the OC-water partition coefficient, $f_{B C}$ is the fraction $\mathrm{BC}, K_{F, B C}$ is the Freundlich $\mathrm{BC}$-water partition coefficient $\left[\left(\mu \mathrm{g} / \mathrm{kg}_{\mathrm{BC}}\right) /(\mu \mathrm{g} / \mathrm{L})^{n}\right]$, and $n$ is the BC Freundlich coefficient. 
By applying eq. 4 , it can be observed that BSAF is dependent on $C_{W}$ and the BC/TOC ratio (Fig. 4). In the modeling representative values for the parameters in eq. 4 are assumed (the ones for Ketelmeer sediment). Figure 4 also shows that a $\mathrm{BC}$ sorption framework can also account for the often-observed difference in BSAF between (mostly planar) PAHs and (mostly nonplanar) PCBs. It is therefore concluded that it is important to include the contribution of $\mathrm{BC}$ when assessing the overall in situ sorption characteristics of a given soil or sediment.
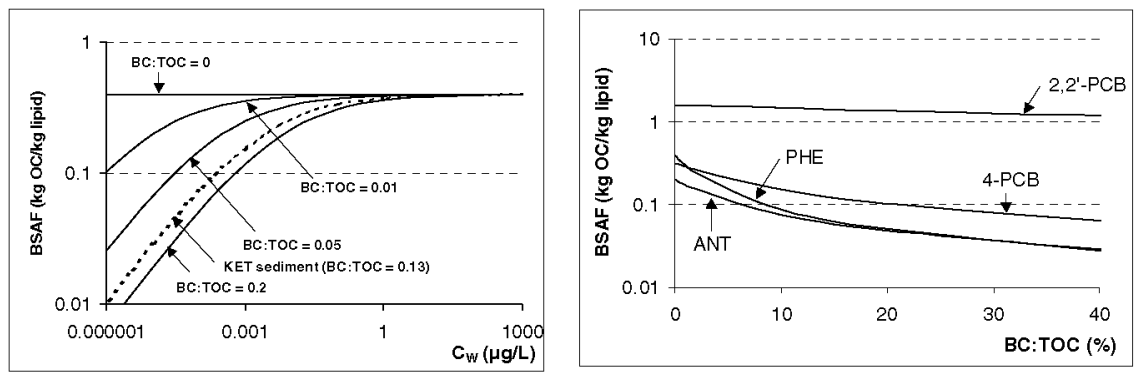

Fig. 4. Left panel: BSAF as a function of $\mathrm{C}_{\mathrm{W}}$ at various $\mathrm{BC}$ percentages; right panel: BSAF as a function of $f_{B C} / f_{T O C}$ (at a constant $C_{W}$ of $0.1 \mathrm{ng} / \mathrm{L}$ ). The modeling parameters were according to the constrained environmental BC sorption parameters. Reprinted from [94]. Copyright 2005 Society of Environmental Toxicology and Chemistry.

\subsection{Bioavailability of hydrophobic organic chemicals for microbial degradation in sediments}

Microbial degradation is the principal removal mechanism of environmental organic chemicals. However, particularly in the terrestrial environment and the sediments of lakes and rivers, the biochemical activities of bacteria and other microorganisms are limited by the relative inaccessibility of these theoretically degradable compounds. The limited contact between bacteria and the chemicals is caused by either sorption and sequestration in the solid phase or dissolution in non-aqueous phase liquids (NAPLs) [95]. All these phenomena lead to low bioavailable concentrations controlling the degradation rate by the existing biomass and in case of being utilized as carbon substrate, the maintenance of existing biomass and the formation of new biomass capable of contaminant degradation [96]. In sediments and watersaturated soils, the problem of unavailable carbon substrates may also go along with limited availability of electron acceptors that are suited to bring about the mineralization of the contaminants. Particularly the degradation of reduced and thermodynamically stable compounds such as aromatic hydrocarbons suffers from both their tendency to sorb to the solid phase and the requirement of either oxygen or alternative, similarly suited electron acceptors.

With respect to the risk of sediment contamination with organic contaminants and the possibility to remove it with biological means, two sets of questions are of high timeliness because they have not yet been conclusively answered: (i) Is the availability of a contaminant for microbial degradation equal to its availability for accumulation in organisms and 
concomitant exertion of toxic effects? Are those environmental chemicals that are inaccessible for microbial degradation also unlikely to get into contact with the tissues and cells of organisms that would suffer from such contact? (ii) Does the bioavailability of a contaminant only depend on the rates at which it desorbs from the solid phase? Do microorganisms just have to wait for the contaminant to appear in the aqueous phase they inhabit? Or have bacteria developed mechanisms allowing them to mobilize a compound beyond the rates of passive desorption from the inaccessible state?

The first set of questions can be approached by an empirical comparison of microbial biodegradation and the accumulation of contaminant in the tissues and cells of target organisms. Alternatively, modelling and theoretical considerations can be of help. Both approaches are presently applied in the frame of the European project ABACUS, in which microbiologists and ecotoxicologists are involved. It appears to be clear already that bioavailability is highly subjective and depends on the kind of organism, its behaviour, type of nutrition, surface to volume ratio and most importantly for the above question, whether the contaminant is consumed while exerting its bioactivity or not. Consumptive processes rely on a steady re-supply of the contaminant in order to maintain the bioavailability whereas nonconsumptive processes strive towards equilibrium, meaning that high bioavailability can be kept over extended periods with a static amount of chemical. Part of the subjectivity of bioavailability can be explained when one accepts that environmental chemicals act as selective factors for the evolution of organisms. Whereas those microorganisms that evolved features facilitating the active acquisition of poorly bioavailable chemicals (see below) possess a selective advantage, evolution of such bioavailability-promoting features by target organisms suffering from toxic effects of environmental chemicals are less likely.

The second set of questions can be tackled most easily by examining the physicochemistry and microbial physiology of biodegradation under bioavailability restrictions. The studies may perform model calculations taking into account the kinetics of microbial degradation and microbial biomass formation as functions of available contaminant concentrations, in combination with the kinetics of contaminant delivery as a function of driving forces, such as microbial degradation. Experimental results, model calculations and theoretical considerations lead to conclude that microbes can be at least as efficient as abiotic mechanisms in mobilizing per se inaccessible contaminants. For example the Tenax ${ }^{\text {(8) }}$ desorbed fraction of aged PAH in sediment was found to correlate well with their biodegradation under optimised conditions [55]. Extraction with cyclodextrin and the surfactant Triton X-100 also correlated well with the biodegradation of PAH. Contaminant desorption from the solid phase occurs when the aqueous concentrations in contact with the sorbent is below the equilibrium concentration. This can be achieved by abiotic extractants as well as by microbial degradation, with the extraction power of the extractant and the specific substrate affinity of the bacteria controlling the release rates respectively. It has been shown that bacteria have evolved extreme affinities for poorly water-soluble substrates that easily compete with chemical extractants [97]. However, unlike chemical extractants, bacteria possess additional features. They may actively and specifically move to the source of the contaminant following increasing concentrations of substrate molecules, upon arrival they may attach to the substrate source upon surface modification or not, they may force the 
release of sorbed contaminant by degrading the sorbent, they may send out carrier molecules, surface-active agents or extracellular enzymes to access and mobilize per se inaccessible organic substrates and they may create movement of the medium containing the substrates [98].

Pollutant-degrading microorganisms can move through the porous matrix of soils and sediments to degrade pollutants localized at distant places, increasing therefore bioavailability. This mobilization can be mediated by water flow [99] or by chemotaxis [100]. In the latter study, strains capable to degrade different PAHs (naphthalene, phenanthrene, anthracene, pyrene and fluoranthene) were isolated from rhizosphere soils contaminated with coal tar and oil. Three representative Pseudomonas strains were selected for detailed chemotaxis studies with PAHs (Fig. 5). The chemotactic attraction caused motion rates in the order of $1 \mathrm{~mm} / \mathrm{min}$, which is remarkable when compared with the assumed average distance between individual microcolonies in soil $(100 \mathrm{~mm})$. This suggests that chemotactic PAHdegrading bacteria may be able to access in a few seconds a significant fraction of the waterfilled pore volume that immobilized bacterial colonies cannot exploit. It is likely that chemotactic bacteria can detect distant PAH concentration gradients created by desorption from solid particles, and adhere to the source of the pollutant where they can degrade it at higher rates.
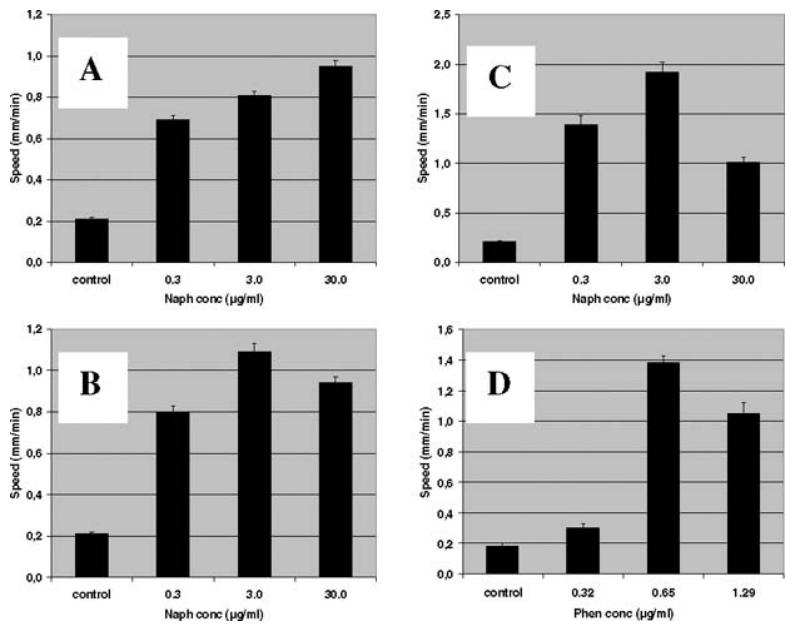

Fig. 5. Chemotaxis towards PAHs of the soil strains Pseudomonas alcaligenes 8A (A, naphthalene), $P$. stutzeri $9 \mathrm{~A}(\mathrm{~B}$, naphthalene) and $P$. putida 10D (C, naphthalene and D, phenanthrene). Reprinted with permission from [100]. Copyright 2003. Elsevier.

An example of the role of adhesion on biodegradation has been shown recently with NAPLs [101]. NAPLs such as creosote or coal tar, often remain as a free phase in the environment after massive contamination, and influence the bioavailability of PAHs. The biodegradation of PAHs present in NAPLs has been found to be severely limited by the slow kinetics of abiotic mass transfer or partitioning of these hydrophobic compounds into the aqueous phase. However, adhesion to the NAPL-water interface seems to be the predominant mechanism by which degrading bacteria can accelerate the already slow release of these 
hydrophobic pollutants (Figure 6). The results showed that strain Sphingomonas sp. LH128 is capable of mineralizing phenanthrene initially present in a NAPL (hepta-methylnonane) at a higher rate than the predicted by abiotic partitioning (Fig. $6 \mathrm{~A}$, solid line). The addition of the adhesion-inhibiting agent Triton ${ }^{\circledR} \mathrm{X}-100$ suppressed this phase of maximum mineralization rate, and induced maximum mineralization rates that were not statistically different to partitioning rates (Fig. 6B).

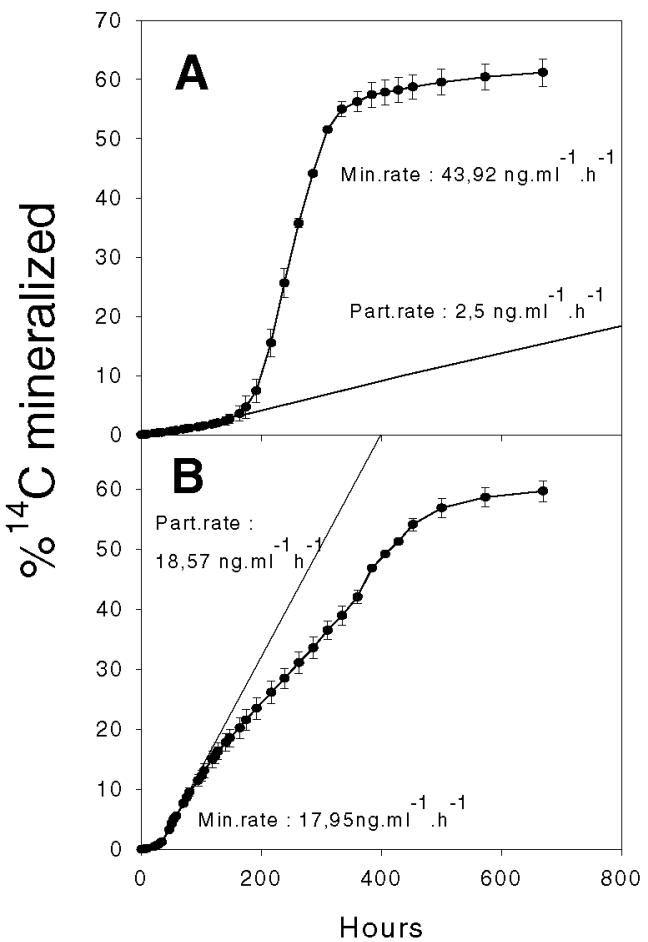

Fig. 6. Mineralization of phenanthrene in HMN without (A) and with (B) Triton ${ }^{\mathbb{B}} \mathrm{X}-100$. Reprinted with permission from [101]. Copyright 2003 American Chemical Society.

Bacteria can also mobilize hydrophobic compounds by promoting their solubility through surface-active compounds or biosurfactants. The biodegradation of phenanthrene by the biosurfactant-producing strain Pseudomonas aeruginosa 19SJ, isolated from a PAHcontaminated soil, was investigated in experiments with the compound present as crystals [102]. Growth on solid phenanthrene exhibited an initial phase not limited by dissolution rate, and a subsequent, carbon-limited phase (Fig. 7A). Rhamnolipid biosurfactants (rhamnose equivalents - RE) were produced from solid phenanthrene at concentrations that exceeded the critical micelle concentration (CMC) determined with purified rhamnolipids (50 mg RE/ml). The biosurfactants caused a significant increase in dissolution rate and pseudosolubility of phenanthrene (Fig. 7B). The results suggest that the biodegradation of solid phenanthrene by $P$. aeruginosa $19 \mathrm{SJ}$ was not exclusively governed by abiotic mass transfer of the compound 
into the water phase, but changes in this mass transfer, derived from the physiology of the organism, lead to an increased bioavailability.
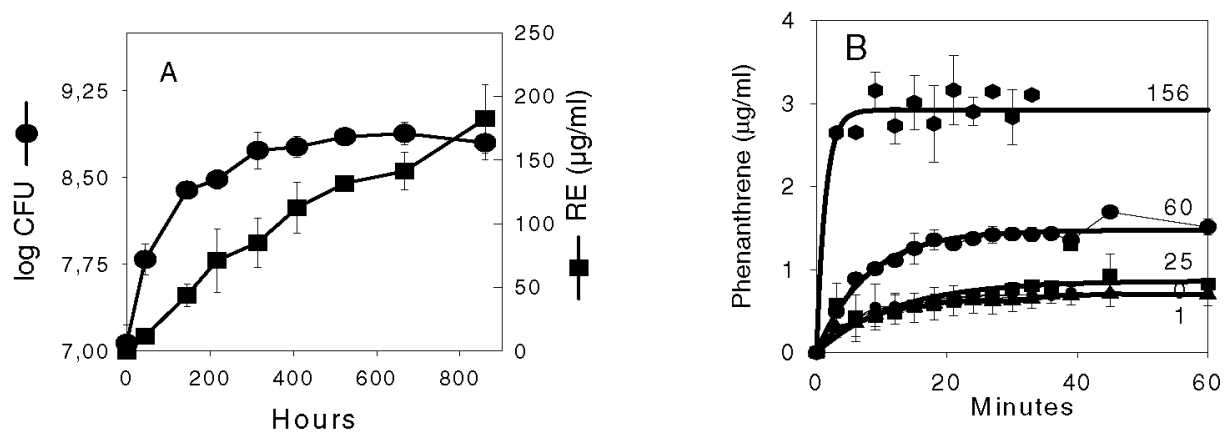

Fig. 7. A, growth (as $\log$ CFU, colony forming units) and production of rhamnolipids by $P$. aeruginosa 19SJ from $10 \mathrm{mg} / \mathrm{ml}$ solid phenanthrene. B, Effect of purified rhamnolipids from $P$. aeruginosa 19SJ on dissolution of $10 \mathrm{mg} / \mathrm{ml}$ solid phenanthrene (numbers express the concentration of rhamnolipids in $\mu \mathrm{gRE} / \mathrm{ml}$.). Reprinted with permission from [102] Copyright 2001 Blackwell Publishing.

\section{METHODS TO DETERMINE BIOAVAILABLE FRACTIONS OF CONTAMINANTS IN SEDIMENTS}

Estimating the bioavailable fraction of metals in sediments is a difficult task. Several approaches have been tried before with various levels of success. These include, for example, the extraction with weak acids and extraction by adjusting to $p H$ levels in the gut of organisms [103, 104]. From the geochemical perspective, the form of the association of metals with mineral and organic matrices determines the biological and physico-chemical availability, mobilization and transport of metals. The sequential selective extraction methods distribute metals between various operationally defined fractions or chemical forms. These fractions likely occur under various environmental conditions and can be used to estimate mobility and bioavailability of the metals [105]. Although the sequential extraction procedures are valid to describe the distribution and transformation of metals species in various media and have been widely used as useful tool for predicting long-term adverse effects from contaminated solid material, it is well known that there are several limitations associated with these procedures [106]. These limitations are mainly related with the samples treatment, the use of appropriated reagents and the provoked reactions.

Recently, new measurement approaches have been developed based on diffusive sampling within sediments (suspensions). Ion exchange resins have become available and look promising for this type of work. Notably DGTs (Diffuse Gradients in Thin films) are currently applied to estimate the concentrations of metals in the dissolved phase sediment pore waters $[107,108]$. The DGT technique depends on the diffusion of labile ions through a 
gel (polyacrylamide hydrogel) where after they are bound by a chelating resin (Chelex absorbent). It can be used for sampling dissolved metals in the water mass (in a form of small disk) or for sampling metals in the pore waters of sediments (by inserting the DGT probe into the sediments). This device allows minimum disturbance of the sampled medium and induces a flux from the pore water that can be related to the elemental concentration in the sampled medium. Several advantages of the DGT technique are: 1) it collects about 30 metal ions in waters at $\mathrm{pHs}$ from $4.7-6 ; 2$ ) measured diffusion coefficients in the gel are close to those for ions in water; 3 ) it is little affected by environment factors ( $p H$, pressure, salinity, temperature); 4) the diffusion gel resistance is about 10-15\% and high sampling capacity (up to months without overloading); 5) high sensitivity with LOD from $0.001-0.1 \mu \mathrm{g} \cdot \mathrm{L}-1$ per $24 \mathrm{~h}$ [109]. Although the DGT sampler may provide a new tool for assessment of reactive metal ions in water and be particularly relevant for integrative use with biological effects measurements, no single method seems sufficiently developed to reach any firm conclusions. More experience and information seems to be required.

A number of methods have been developed to measure bioavailable fractions of organic contaminants. The magnitude of the rapidly desorbing fraction of PAHs in sediment was found to be a predictor of the extent of short-term bioremediation [110].

It was recently reported for 23 different organic compounds in 5 soils and 5 sediments [111] that BSAF-values for two organisms varied over more than two orders of magnitude (indicated by the dashed line in Fig. 8, derived from data in [111]) and that many of these values were substantially less than the theoretical value (dotted line in Fig. 8). However, the variation in BSAF-values was substantially reduced when the amount extracted from soils or sediment by Tenax ${ }^{1}$ in $6 \mathrm{~h}$ was used instead of the total solvent extractable amount for the calculation of BSAF-values; the median BSAF-value was virtually equal to the theoretical value. That is in line with expectations since (i) earlier it was shown that Tenax extracts in 6 $\mathrm{h}$ about $50 \%$ of the fraction absorbed by sediments [112] and (ii) Kraaij et al. demonstrated [113] that variation in BSAF-values can be explained by the variation in the fraction absorbed by sediments 


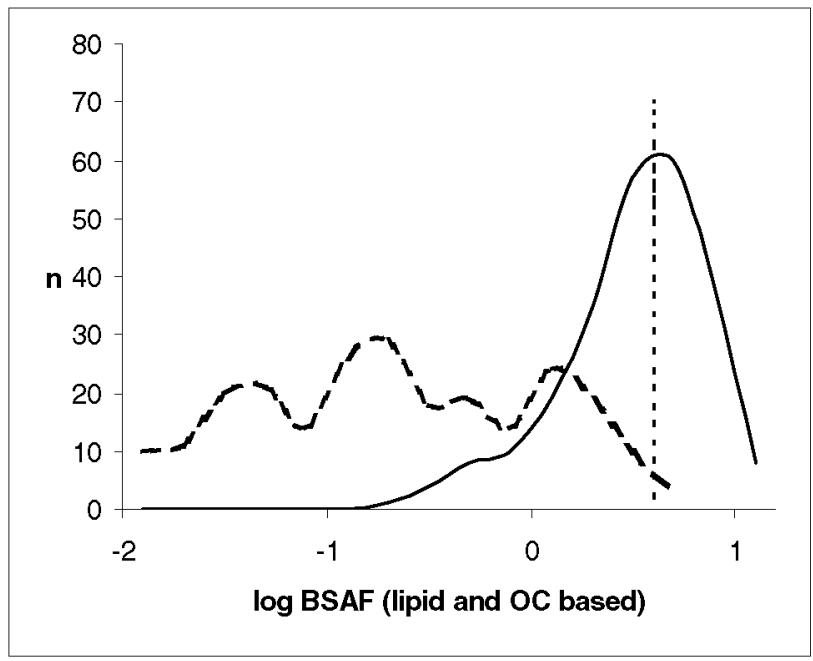

Fig. 8. Log BSAF frequency distribution for 23 organic compounds in a benthic organism and in a soil organism in 5 soils and 5 sediments. Dashed line: BSAF-values based on solvent extraction of the soils and sediments; drawn line: based on amount extracted by Tenax ${ }^{B}$ in $6 \mathrm{~h}$; dotted line: theoretical value, data from [1 1111$]$.

Another approach for risk assessment is to measure the freely dissolved concentration in interstitial or pore water and compare that result directly with the waterborne quality standard. Furthermore, the concentration in the freely dissolved phase resulting from e.g. equilibrium partitioning is an indicator for the potential of a sediment to contaminate the surrounding aqueous environment. Kraaij et al. also demonstrated [113] that in the presence of sediment equilibrium concentrations in organisms can be predicted from freely dissolved concentrations in water, determined by solid phase micro-extraction (SPME) and theoretical bioconcentration factors for accumulation into organisms from water. On a soil or sediment organic carbon content basis, partition coefficients for absorption hardly vary. Therefore, there is conceptually no difference between estimating equilibrium concentrations in organisms from either freely dissolved concentrations in water or the amount absorbed in sediment or soil. Furthermore, Morrison et al found [114] that concentrations of DDT, DDE, and DDD in Eisenia foetida taken up from a soil correlated with the amount taken up by $\operatorname{Tenax}^{\circledR}$ resin in $14-16 \mathrm{~h}$. 


\section{USE OF BIOAVAILABILITY DATA IN ASSESSMENT OF THE RISKS OF CONTAMINANTS IN SEDIMENTS}

In many cases, sediment quality standards are derived from water quality standards by multiplying the latter with a sediment-water partition coefficient. Usually, these partition coefficients are for the process of absorption, not adsorption. Therefore, for an assessment based on sediment quality standards and correcting for reduced bioavailability, the concentration in sediment extracted by Tenax ${ }^{\mathbb{B}}$ in $6 \mathrm{~h}$ multiplied by 2 can be compared with these sediment quality standards. Alternatively, freely dissolved concentrations in sediment (or soil) pore water, can be compared to water quality standards. A word of warning seems to be in place. In some countries, water quality standards have been derived for water including a normalized concentration of suspended matter. In suspended matter, sorption may be predominantly by non-linear adsorption because it has been shown for a recently deposited sediment that organic contaminants were predominantly sorbed in the very slowly desorbing domain [115]. The application of those water quality standards to total concentrations in water will ignore the reduced bioavailability of compounds associated with suspended matter and will, hence, overestimate risks of contamination. Furthermore, those water quality standards should not be used for the comparison with freely dissolved concentrations in pore water.

For the assessment of sediment contamination, bioassays are also occasionally employed. Some of these bioassays involve solvent extraction of organic contaminants from sediment. To account for reduced bioavailability, extraction by Tenax ${ }^{\circledR}$ seems to be a better choice.

Measured bioavailable concentrations in sediment give information on environmental risks of contamination levels only at the time and place of sampling, because bioavailable concentrations may change in time if the environmental conditions change. At present, it is not yet possible to quantitatively predict these changes. These changes may be induced by changes in the type and concentration of natural organic compounds competing for adsorption sites. Natural organic compounds that may compete for adsorption sites are, for instance, methane, humic and fulvic compounds, low molecular weight aliphatic and aromatic carboxylic acids. For example, application of sediment to soil may substantially alter the environmental conditions of the sediment. Production of methane may then cease, and, methane initially present may disappear. As a result, competition for adsorption sites by methane may decrease leading to decreased bioavailability in time. On the other hand, it cannot be excluded that concentrations of other competing natural organic compounds in sediment-amended soil may be higher than in the original sediment, due to their production in the root zone, for instance. Competition due to the occurrence of high concentrations of these natural organic compounds may counteract the decrease in bioavailability by decreasing methane production. Therefore, for the environmental risk assessment of sediments to be removed from the waterbed, research on the quantification of adsorption competition by natural organic compounds is needed to eventually design techniques and models for the prediction of the influence of changing environmental conditions on bioavailability. Furthermore, the understanding of adsorption competition is instrumental in designing amendment techniques for in situ reduction of organic contaminant bioavailability in sediments after removal from the waterbed. 


\section{CONCLUSIONS}

Recent research has lead to increased insight into the mechanisms of sorption of contaminants, both metals and hydrophobic organic contaminants, and their consequences for the bioavailability of these contaminants. The combination of the SEM-AVS approach with the biotic ligand model is a promising method to relate concentrations of metals at the site of toxic action with the bioavailable concentrations in porewater and sediment. Long-term field studies have demonstrated that these approaches are suitable for evaluating and predicting the effect-based bioavailability of metals in sediments

Desorption of hydrophobic organic compounds from sediment can be described on the basis of three distinct kinetic steps which appear to be related to two domains of sediment organic matter. One of these domains, amorphous organic matter, such as humic and fulvic substances and lignin, sorbs HOCs linearly with rapid desorption kinetics. In contrast, the slowly and very slowly desorbing factions of HOCs appear to be related to non-linear sorption to condensed organic matter, such as coal, soot and kerogen. Because of its non-linear nature, sorption to condensed organic matter is particularly important at low aqueous concentrations of the contaminants. Sorption to soot and other forms of black carbon is particularly strong for planar compounds such as PAHs.

Based on observations with different organisms and both spiked and field-contaminated sediments, the bioavailability of HOCs for accumulation in sediment organisms appears to correlate well with the linearly sorbed, rapidly desorbing fraction. Similarly, the bioavailability of sorbed HOCs for microbial degradation also seems to be restricted to the linearly sorbed fraction. However, microbial mechanisms to enhance uptake of substrates, such as chemotaxis and adhesion may lead to degradation rates higher than those predicted from desorption rates. Whether these mechanisms can influence the bioavailability of the nonlinearly sorbed HOCs remains to be seen.

Over the last few years, a number of biomimetic methods have been developed that mimic the way that organism take up contaminants from sediment and sediment pore water. Some of these methods, such as negligible-depletion SPME and Tenax ${ }^{\circledR}$-based desorption have been used successfully to predict accumulation and degradation of HOCs in sediments in pilot studies. Comparable methods for metals use ion exchange resins and the DGTs. These methods seem to be very promising for application in assessments of the risks and impact of sediment contamination.

\section{REFERENCES}

[1] P.G.C. Campbell, A.G. Lewis, P.M. Chapman, A.A. Crowder, W.K. Fletcher, B. Imber, S.N. Luoma, P.M. Stokes and M. Winfrey, in NRCC Associate Committee on Scientific Criteria for Environmental Quality and Committee on Marine Analytical Chemistry of the NRCC Marine Analytical Chemistry Standards Program, 1988.

[2] P.G.C.Campbell and A. Tessier, in A. Boudon, and F. Robeyre (Eds.) Aquatic Ecotoxicity: Fundamental Concepts and Methodologies, CRC Press, Boca Raton, FL, 1994, pp. 125. 
[3] R. Davies-Colley, J.P. Nelson, and K.J. Williamson, Environ. Sci. Technol. 18 (1984) 491.

[4] W. Fan, and W.-X Wang, Environ. Toxicol. Chem. 22 (2003) 2659.

[5] E.A. Jenne, in Symposium on Molybdenum in the Environment, Vol. 2 M. Dekker, Inc., New York, 1977, pp. 415.

[6] S.N. Luoma, and J.A. Davis, Marine Chemistry 12 (1983) 159.

[7] ASTM, E. 1367-92, Annual Book of ASTM Standards, Philadelphia, PA, 1994, pp. 1161.

[8] G.A. Burton Jr., Environ. Toxicol. Chem., 10 (1991) 1585.

[9] G.A. Burton Jr., M.K. Nelson and C.G. Ingersoll, in G.A. Burton, Jr. and P. Lewis. P (Eds.), Sediment Toxicity Assessment, CRC, Boca Raton, FL, 1992, pp. 213.

[10] P.M. Chapman, F. Wang, C. Janssen, H.E. and Allen, Draft report for Kennecott Mines, 1997.

[11] P.M. Chapman, F. Wang, C.R. Janssen, R.R. Goulet and C.N. Kamunde, Human Eco. Risk Assess. 9 (2003) 641.

[12] P.R. Paquin, J.W. Gorsuch, S. Apte, E. Batley, K.C. Bowles, P.G.C. Campbell, C.G. Delos, D.M. Di Toro, R.L. Dwyer, F. Gonzales, G.G. Goss, C. Hogstrand, C.R. Janssen, J. Mc Geer, R.B. Naddy, R.C. Payle, R.C. Santore, U. Scheinder, W.A. Subblefield and C.W. Wood. Comp. Biochem. Physiology, 133 (2002) 3.

[13] D.M. Di Toro, C.S. Zarba, D.J. Hansen, W.J. Berry, R.C. Swartz, C.E. Cowan, S.P. Pavlou, H.E. Allen, N.A. Thomas, and P.R. Paquin, Environ. Toxicol. Chem., 10 (1991) 1541.

[14] L. Hare, A. Tessier and U. Borgmann, Human Eco. Risk Assess., 9 (2003) 779.

[15] L.A. Warren, A. Tessier and L. Hare, Limnol. Oceanogr., 43 (1998) 1442.

[16] A.-K. Wiklund and B. Sundelin, Environ. Toxicol. Chem., 21 (2002) 1219.

[17] G.T. Ankley, M.K. Schubauerberigan and J.R Dierkes. Environ. Toxicol. Chem., 10 (1991) 1359.

[18] W.J. Berry, D.J. Hansen, J.D. Mahony, D.L. Robson, D.M. Di Toro, B.P. Shipley, B. Rogers, J.M. Corbin, W.S. and Boothman, Environ. Toxicol. Chem., 15 (1996) 2067.

[19] D.M. Di Toro, J.H. Mahony, D. J. Hansen and W.J. Berry, Environ. Toxicol. Chem., 15 (1996) 2187.

[20] G.T. Ankley, D.M. Di Toro, D.J. Hansen and W.J. Berry, Environ. Toxicol. Chem., 15(1996) 2056.

[21] T.H. De Witt, R.C. Swartz, D.J. Hansen, D. McGovern, and W.J. Berry, Environ. Toxicol. Chem., 15 (1996) 2095.

[22] D.M. Di Toro, J.H. Mahony, D.J. Hansen, K.J. Scott, M.B. Hicks, S.M. Mayr and M. Redmond, Environ. Toxicol. Chem., 9 (1990) 1487.

[23] A.S. Green, G.T. Chandter, and E.R. Blood, Environ. Toxicol. Chem., 12 (1993) 1497.

[24] D.J. Hansen, J.D. Mahony, W.J. Berry, S.J. Benyi, J.M. Corbin, S.D. Pratt, D.M. Di Toro, and M.B. Abel, Environ. Toxicol. Chem., 15 (1996) 2126.

[25] L. Hare, R. Carignan, and M.A. Huertadiaz, Limnol. Oceanogr., 39 (1994) 1653.

[26] K. Liber, D.J. Call, T.P. Markee, K.L. Schmude, M.D. Balcer, F.W. Whiteman and G.T.Ankley, Environ. Toxicol. Chem., 15 (1996) 2113.

[27] C.E. Pesch, D.J. Hansen, W.S. Boothman, W. J. Berry and J.D. Mahony, Environ. Toxicol. Chem., 14 (1995) 129.

[28] P.K. Sibley, G. T. Ankley, A.M. Cotter, and E.N. Leonard., Environ. Toxicol. Chem., 15 (1996) 2102. 
[29] B.G Lee, J.S Lee, S.N. Luoma, H.J. Choi and C.H Koh, Environ. Sci. Technol., 34 (2000) 4517.

[30] G.A. Burton Jr, L.T.H. Nguyen, C. Janssen, R. Baudo, R. Mc William, B. Bossuyt, M. Beltrami and A. Green, Environ. Toxicol. Chem., 23 (2004) 541.

[31] D.M. Di Toro, J.M. McGrath, D.J. Hansen, W. J., Berry, P.R.,, Paquin, R. Mathew, K.B. Wu and R.C. Santore, Environ Toxicol. Chem., 23 (2004) 2410.

[32] D.M. Di Toro, H.E. Allen, H.L. Bergman, J.S. Meyer, P.R. Paquin and R.C. Santore, Environ. Toxicol. Chem., 20 (2001) 2388.

[33] G.K. Pagenkopf, Environ. Sci. Technol., 17 (1983) 342.

[34] K.A.C. De Schamphelaere and C.R. Janssen, Environ. Sci. Technol., 36 (2002) 48.

[35] K.A.C. De Schamphelaere and C.R. Janssen, Comparative Biochemistry and Physiology C, 133 (2002) 243 .

[36] K.A.C. De Schamphelaere, F.M. Vasconcelos, D.G. Heijerick., F.M.G. Tack, K. Delbeke, H.E. Allen and C.R. Janssen, Environ. Toxicol. Chem., 22 (2003) 2454.

[37] K.A.C. De Schamphelaere and C.R. Janssen, Environ. Toxicol. Chem., 23 (2004) 1115.

[38] K.A.C. De Schamphelaere and C.R. Janssen, Environ. Toxicol. Chem., 23 (2004) 1365.

[39] K.A.C. De Schamphelaere and C.R. Janssen, Environ. Toxicol. Chem., 23 (2004) 2029.

[40] K.A.C. De Schamphelaere, F.M. Vasconcelos, H.E. Allen and C.R. Janssen, Environ. Toxicol. Chem., 23 (2004) 1248.

[41] D.G. Heijerick, K.A.C. De Schamphelaere and C.R. Janssen, Environ. Toxicol. Chem. 21 (2002) 1309.

[42] D.G. Heijerick, K.A.C. De Schamphelaere and C.R. Janssen C.R, Comparative Biochemistry and Physiology C - Toxicology, 133 (2002) 207.

[43] S. W. Karickhoff, in R.A. Baker (Ed.) Contaminants and Sediments, Vol. 2, Ann Arbor Press, Ann Arbor, MI, 1980 p. 193.

[44] C.T. Chiou, L.J. Peters and V.H. Freed, Science, 206 (1979) 831.

[45] W. Huang, T.M. Young, M.A. Schlautman, H. Yu, H. and W.J. Weber, Jr. Environ. Sci. Technol., 31 (1997) 1703.

[46] H.K. Karapanaganioti, S. Kleineidam, D.A. Sabatini, P. Grathwohl, and B. Ligouis, Environ. Sci. Technol., 34 (2000) 406.

[47] G. Xia and W.P. Ball, Environ. Sci. Technol., 33 (1999) 262.

[48] J.J. Pignatello and B. Xing, Environ. Sci. Technol., 30 (1996) 1.

[49] G. Cornelissen, H. Rigterink, P.C.M. van Noort and H.A.J. Govers, Environ. Toxicol. Chem., 19 (2000) 1532.

[50] S.E. McGroddy and J.W. Farrington, Environ. Sci. Technol., 29 (1995) 1542.

[51] T.D. Bucheli and Ö. Gustafsson, Environ Toxicol. Chem., 20 (2001) 1450.

[52] R.M. Allen-King, P. Grathwohl and W.P. Ball, W.P. Adv. Wat. Res., 25 (2002) 985.

[53] W. Huang, P. Peng, Z. Yu and J. Appl. Geochem., 18 (2003) 955.

[54] R.D. Luthy, G.R. Aiken, M.L. Brusseau, D.S.Cunningham, P.M. Gschwend, J.J. Pignatello, M. Reinhard, S.J. Traina, W.J. Weber Jr. and J.C. Westall, Environ. Sci. Technol., 31 (1997) 3341.

[55] M.P. Cuypers, J.T.C. Grotenhuis, K.G.J. Nierop, E. Maneiro Franco, A. de Jager and W.H. Rulkens, Chemosphere 48 (2002) 919.

[56] M.P. Cuypers, thesis Wageningen University (2001).

[57] B. Xing, W.B. McGill, M.J. Dudas, Chemosophere, 34, (1994) 145. 
[58] B. Xing, W.B. McGill, M.J. Dudas, Environ. Sci. Technol., 28 (1994) 1929.

[59] C.T. Chiou, R.L. Malcolm, T.I. Brinton, D.E. Kile, Environ. Sci. Technol., 20 (1986) 502.

[60] F. De Paolis and J. Kukkonen, Chemosphere 34, (1997) 1693.

[61] P. Grathwohl, Environ. Sci. Technol. 24 (1990) 1687.

[62] W.Huang and W.J. Weber Jr., Environ. Sci. Technol. 31 (1997) 2562.

[63] D.E. Kile, R.L. Wershaw and C.T. Chiou, Environ. Sci. Technol. 33 (1999) 2053.

[64] M.T.O. Jonker and A.A. Koelmans, Environ. Sci. Technol., 36 (2002) 3725.

[65] M.T.O. Jonker and A.A. Koelmans, Environ. Sci. Technol., 35 (2001) 3742.

[66] T.D. Bucheli and Ö. Gustafsson, Environ. Sci. Technol., 34 (2000) 5144.

[67] A. Accardi-Dey and P.M. Gschwend, Environ. Sci. Technol., 37 (2003) 99.

[68] J.J. Middelburg, J. Nieuwenhuize and P. van Breugel, Mar. Chem., 65 (1999) 245.

[69] Ö. Gustafsson and P.M. Gschwend, Geochim. Cosmichim. Acta, 62 (1998) 465.

[70] Ö. Gustafsson, T.D. Bucheli, Z. Kukulska, M. Andersson, C. Largeau, J.N. Rouzard, C.M. Reddy and T.I. Eglinton, Global Biogeochem. Cycles, 15 (2001) 881.

[71] G. Cornelissen and Ö. Gustafsson, Environ. Sci. Technol., 38 (2004) 148.

[72] G. Cornelissen, Z. Kukulska, S. Kalaitzidis, K. Christanis and Ö. Gustafsson, Environ. Sci. Technol., 38 (2004) 3632.

[73] G. Cornelissen, M. Elmquist, I. Groth and Ö. Gustafsson, Environ. Sci. Technol., 38 (2004) 3574.

[74] P.C.M. van Noort, M.T.O. Jonker and A.A. Koelmans, Environ. Sci. Technol., 38 (2004) 3305.

[75] P.C.M. van Noort, Environ. Toxicol. Chem., 22 (2003) 1179.

[76] G. Cornelissen, P.C.M. van Noort and H.A.J Govers, Environ.Toxicol.Chem., 16 (1997) 1351.

[77] G. Cornelissen, P.C.M. van Noort, J.R. Parsons and H.A.J. Govers, Environ.Sci.Technol., 31 (1997) 454.

[78] W. Huang and W.J. Weber, Jr. Environ. Sci. Technol., 31 (1997) 2562.

[79] K.J. Rockne, L.M. Shor, L.Y. Young, G.L.Taghon and D.S. Kosson, Environ. Sci. Technol., 36 (2002) 2636.

[80] U. Gosh, J.W. Talley and R.G. Luthy, Environ. Sci. Technol., 35 (2001) 3468.

[81] Y. Zhang, R.S.S. Wu, H.S. Hong, K.-F. Poon and M.H.W. Lan, Environ. Toxicol. Chem., 19 (2000) 2431.

[82] T.E.M. ten Hulscher, B.A. Vrind, H. van den Heuvel, L.E. van der Velde, P.C.M.van Noort, J.E.M. Beurskens and H.A.J. Govers, Environ. Sci. Technol., 33 (1999) 126.

[83] R. Kraaij, P. Mayer, F.J.M. Busser, M. van het Bolscher, W. Seinen, J. Tolls and A. Belfroid, Environ Sci Technol., 37 (2003) 268.

[84] G. Cornelissen, H. Rigterink, B.A. Vrind, Th.E.M.. ten Hulscher, M.A. Ferdinandy and P.C.M. van Noort PCM, Chemosphere 35 (1997) 2405.

[85] G. Cornelissen, M. van der Pal, P.C.M. van Noort and H.A.J. Govers, Chemosphere, 39 (1999) 1971.

[86] H. van den Heuvel and P.C.M. van Noort, Chemosphere, 53 (2003) 1097.

[87] P.C.M. van Noort, G. Cornelissen, Th.E.M. ten Hulscher, and A. Belfoid, Environ Toxicol Chem, 21 (2002) 2326.

[88] P.C.M. van Noort, G. Cornelissen Th.E.M. ten Hulscher, B.A. Vrind, H. Rigterink and A. Belfroid, Wat. Res., 37 (2003) 2317. 
[89] P.F. Landrum, D.C. Gossiaux and J. Kukkonen, Chem. Speciat. Bioavail., 9 (1997) 43.

[90] R.H. Kraaij, S. Ciarelli, J. Tolls, B.J. Kater and A. Belfroid, Environ. Toxicol. Chem., 20 (2001) 1716.

[91] P.F. Landrum and J.A. Robbins, in R. Baudo, J. P. Giesy, and H. Muntau (Eds.), Sediments: Chemistry and Toxicity of In-Place Pollutants, Lewis Publishers, Inc. Ann Arbor, MI., 1990, pp. 237.

[92] J.V.K. Kukkonen, P.F. Landrum, S. Mitra, D.C. Gossiaux, J. Gunnarsson and D. Weston, Environ. Sci. Technol., 37 (2003) 4656.

[93] J.V.K. Kukkonen, P.F. Landrum S. Mitra, D.C. Gossiaux, J. Gunnarsson and D. Weston, Environ. Toxicol. Chem., 23 (2004) 877.

[94] G. Cornelissen and Ö. Gustafsson, Environ. Toxicol. Chem., 24 (2005) 495.

[95] M. Alexander, Environ. Sci. Technol., 34 (2000) 4259.

[96] T.N.P. Bosma, P.J.M. Middeldorp, G. Schraa and A.J.B. Zehnder, Environ. Sci. Technol., 31 (1997) 248.

[97] L.Y. Wick, T. Colangelo-Failla and H. Harms, Environ. Sci. Technol., 35 (2001) 354.

[98] H. Harms and L.Y. Wick, in H. P. van Leeuwen, and W. Koester (Eds.) Physicochemical Kinetics and Transport at Chemical-Biological Interphases, IUPAC Series in Analytical and Physical Chemistry of Environmental Systems. Wiley, Chichester, 2004, p. 401.

[99] M. Lahlou, H. Harms, D. Springael and J.J. Ortega-Calvo, Environ. Sci.Technol., 34 (2000) 3649 .

[100] J.J. Ortega-Calvo, A.I. Marchenko, A. I. Vorobyev and R.V. Borovick, FEMS Microbiol. Ecol., $44(2003) 373$.

[101] M. García-Junco, C. Gomez-Lahoz, J.L. Niqui-Arroyo and J.J. Ortega-Calvo, Environ. Sci.Technol., 37 (2003) 2988.

[102] M. García-Junco, E. De Olmedo and J.J. Ortega-Calvo, Environ. Microbiol., 3 (2001) 561.

[103] V.E. Forbes and T.L. Forbes, Environ. Toxicol. Chem., 16 (1997) 1002.

[104] V.E. Forbes, M.S.H. Andreassen and L. Christensen, Environ. Toxicol. Chem., 20 (2001) 10121021 .

[105] A. Tessier, P.G.C. Campbell and M. Bisson, Anal. Chem., 7 (1979) 844.

[106] U. Förstner, Intern. J. Environ. Anal. Chem., 51 (1992) 5.

[107] H. Zhang and W. Davidson, Anal. Chem., 67 (1995) 3391.

[108] M. Zhang, W. Davidson, S. Miller and W. Tych, Geochem. Cosmochem. Acta, 59 (1995) 4181.

[109] O. Royset in ICES Report WGMS: ICES CM 2004/E02. Ref.: ACM. (2004) p. 91.

[110] G. Cornelissen, H. Rigterink, M.M.A. Ferdinandy and P.C.M. van Noort, Environ.Sci.Technol, 32 (1998) 966.

[1111] Th.E.M. ten Hulscher, J. Postma, P.J. den Besten, G.J. Stroomberg, A. Belfroid, J.W. Wegener, J.H. Faber, J.J.C. van der Pol, A.J. Hendriks and P.C.M. van Noort. Environ. Toxicol. Chem., 22 (2003) 2258.

[112] G. Cornelissen, Th.E.M. ten Hulscher, H. Rigterink, B.A. Vrind and P.C.M. van Noort, Environ. Toxicol. Chem., 20 (2001) 706.

[113] R. Kraaij, Sequestration and bioavailability of hydrophobic chemicals in sediment. Ph.D. Thesis. University of Utrecht. 2001.

[114] D.E. Morrison, B.K. Robertson and M. Alexander, Environ. Sci. Technol., 34 (2000) 709. 
[115] Th.E.M. ten Hulscher, B.A. Vrind, P.C.M. van Noort and H.A.J. Govers, Chemosphere, 49 (2002) 1231. 